\title{
Analysis on Role of New Public Management Concept in China's Administrative Reform
}

\author{
Mengyao Li \\ School of Government, Peking University, Beijing, 100000, China
}

Key words: China's administrative reform, New public management concept, Role, Analysis.

\begin{abstract}
In the new period, as the process of China's administrative reform is deepened, the importance of new public management concept is also gradually highlighted. This concept is introduced from the West; therefore, its application in China's administrative reform must be properly examined and deeply deconstructed. Based on this, this paper takes full account of the actual situation of administrative reform in China, expounds relevant views, and actively learns from specific practices, to further promote the new development of China's administrative reform.
\end{abstract}

\section{Study on new public management concept}

Traditional administrative management measures take political and administrative dichotomy or bureaucratic administrative management theory as the important basis. However, new public management concept consistently innovates and develops based on modern economics and private enterprise management theory. Among them, administrative management advocated by new public management thought not only exists in the form of centralized power, or only relies on supervision and responsibility system to achieve the effective improvement of administrative performance, but requires the government to fully innovate management concept in the administrative management, actively learn from advanced enterprise management ideas and methods, and effectively implement the administrative work ${ }^{[1]}$. Introduce competition mechanism into the government management, to strengthen the government staff's sense of responsibility and working passion in the form of competition, so as to further improve the quality and level of government services for people. In addition, new public management concept requires the government, in the management process, to take the actual needs of customers and the market as an important direction of development, and effectively implement administrative innovation management to improve government performance. At this stage, new public management theory is not yet mature, but also has a certain influence on China's administrative reform.

\section{Basic content of new public administrative concept}

\section{Redefine the relationship between the government and market}

Government departments should actively introduce competition mechanism to ensure the marketization and quasi-commercialization of internal management work. In this way, the quality and level of government public service will also be fully improved. New public management concept, clearly points out that the main reason for the efficiency of government management is the serious lack of competition mechanism. So it is necessary to transform the government with the help of market forces in the context of competition introduced into the market, to ensure that the private sectors can participate in public services, and achieve the overall upgrade of government service level and work efficiency. 


\section{Integration of the relationship between the country and society}

With the help of community funding management and privatization and other means, government's services are more diversified, which provides a certain channel for active participation of private institutions. Through the comprehensive integration of national and social management, actively carry out diversified management work, to further enhance the quality of public goods and service level.

\section{Comprehensive reform of government operating mechanism and method}

New public management concept requires appropriate adjustment of the highly centralized and hierarchical government organizational structure, to achieve the flat and networked government organization ${ }^{22]}$. Among them, reform government behavior evaluation standards, control means and administrative organizations, properly adjust original administrative model and government operating mechanism, based on the overall optimization of government functions, reform institutional organization, and further enhance the effectiveness of government organization work.

\section{Use core strategic capability to improve government competence}

Government departments should adopt flexible working ways to ensure the normal development of work on the basis of low cost. At the same time, fully consider changes of internal and external environment, further enhance the national core strategic capability and realize the overall improvement of the government's competitiveness. At the same time, establish and improve the government management mechanism, to ensure its democratization and legalization, and lay a solid foundation for enhancement of the government capability.

\section{Introduce excellent management approaches and experience of private sectors}

There exists a fundamental difference between the public sector and private sector, but the management and technology within the private sector are equally worth learning. For this, the government should widely absorb the excellent management experience within the private sector, and through the rational introduction of management means, further enhance the service quality and level.

\section{Customer-oriented}

The government should follow customer-oriented concept in the work, and provide the freedom to choose the opportunity to ensure the quality and level of service, and improvement of citizens' satisfaction. Among them, in terms of exchanges between government and citizen, actively change the traditional one-way approach into bidirectional.

\section{Properly relax administrative rules}

New public management concept requires all departments and organizations to accept the supervision and restraint of rules and regulations, in order to ensure the efficiency of their work. However, more demanding rules and regulations may affect the quality and efficiency of organizational work. In this case, in order to improve the efficiency of the work, it is a must to adapt to the changes in the market environment, effectively reform the strict administrative rules, implement management work and achieve the purpose of goal control ${ }^{[3]}$.

\section{Necessity of application of new public management concept in China's administrative reform}

Under the background of new period, with accelerating national economic development, people's daily living standard has been improved. In the context of global economic integration, government functions are also required to keep pace with the times. The government should deepen the reform, and constantly enhance their own service level and quality, to achieve work efficiency improvement, and better meet the development needs of the market economy. In the new situation, the government should study public affairs management in the market environment, strengthen and improve the service quality and level on the basis of innovative administration, and fully promote the 
modernization of the administrative work. Among them, the western public management theory provides a valuable reference for China's administrative reform, such as, market-oriented, and deepening the reform of the government's management functions to provide protection for economic and social development. Thus, the government should rationally learn from the new public management concept.

\section{Role and reference of new public government concept in China's administrative reform}

The so-called new public management concept is based on the western policy, economy and culture, and is widely used in administrative work in western countries. To a certain extent, it improves the efficiency and level of national public management, consistently meets people's demand for public services, accelerates the development of western countries, and enhances their competitiveness ${ }^{[4]}$. Based on this, new concept should be studied in depth and also properly applied based on the domestic development, to improve the level of public service, and enhance China's international competitive strength.

\section{Proper adjustment of the central and local relation}

The contradiction between central and local management always exists in the process of China's reform and development. In the context of the traditional planned economic system, the country's rights are concentrated, the central management is broad and the rules are strict. Economic democracy and political democracy are insufficient. First, the centralized economy mechanism to meet demand for planned economy development; second, administrative centralization political mechanism to achieve political and economic integration; third, the legislative mechanism focusing on political and economic forms. In the context of a high-degree centralization mechanism, the central power is over-concentrated, and the local is in the passive state, deeply controlled, and difficult to express their own needs and will. For the effective treatment of the central and local relations, the focus is to accurately find the dynamic balance between these two, and properly integrate unity and diversity characteristics. Among them, the unity is specifically involved with the function and role of the central government, and it is the unity of domestic market mechanism, tax system, public service standards and macroeconomic management. And diversity is embodied in the role and functions of local governments, requiring according to the actual situation of different regions to implement more diverse and flexible local mechanisms. Reasonably use a series of measures, effectively expand local autonomy, and confirm it under the role of laws and regulations. At present, the taxation mechanism implemented in China has effectively realized the division of central and local power, which can not only fully mobilize the enthusiasm of local work, but also play the role of the central. For this purpose, continuous improvement is required to play an even greater advantage.

\section{Effective separation of government decision-making and executive functions}

China's administrative management is affected by its own unique characteristics. It is necessary to achieve effective reform of the administrative system to separate decision-making and implementation. This is somewhat different from the bureaucracy reform in western countries. First of all, within Chinese government agencies the decision-making and executive functions cannot be completely, but properly separated. Specifically, on the basis of ensuring that the executive heads moderately control the executive agencies, executive agencies still need to carry out work related to contracts, performance, legal system and integrated management ${ }^{[5]}$. Second, executive agencies supervisor should combine with the socialist market economic system, to effectively resolve problems about contradictions of law enforcement and departmental interests, and even the quality of law enforcement. For this, it is necessary to establish a comprehensive executive agency as a starting point. Finally, the separation of government decision-making and executive functions cannot be accomplished overnight. In the whole process, the system of public administration in China can be continuously improved, at the same time, socialist democracy and the rule of law will be perfected, 
and the quality of civil servants and the educational level of the whole nation can be effectively enhanced.

In the process of moderately separating decision-making and executive functions, it is necessary to actively establish a comprehensive executive agency, and then to strictly regulate the government's behaviors so as to effectively change functions of the government. In this way, the department can be out of the executive affairs, and put more energy and time on the policy and guidelines. At the same time, proper separation of decision-making and executive functions, also can regulate administrative behaviors, comprehensively strengthen management transparency, and keep in line with institutionalization and openness demand of market economy development administrative behaviors, as far as possible to avoid corruption.

\section{Effective reform of government organization}

Traditional government agency has strong mechanical and closed features, in which, there are strictly hierarchical superior-subordinate relation, high-degree centralization of power, and serious lack of flexible standards. Therefore, it has been difficult to adapt to changes in modern social environment, and has had a serious impact on administrative efficiency. After the construction of the socialist market economic system, objectives of China's administrative reform include, to follow needs of the market economy to create administrative mechanisms; to improve efficiency and coordination of operations to ensure standardized behaviors; to continue to improve civil servant system and form high-quality professional administrative cadre team. The main purpose of this administrative reform is to ensure that the government can better adapt to the administrative mechanism, and strengthen the coordination of the operation of the mechanism, to achieve effective improvement of government administrative efficiency and public production capacity.

\section{Promote democracy of management work}

Citizens' participation in the management is an important principle in China's administrative reform. Chinese citizens are not only the main consumers of public services, but also play a key role in supervising public services; therefore they should exercise their rights in participation in management. In the analysis and research of management psychology, it can be found that citizens and low-level civil servants can most deeply know about the public needs, therefore, introduction of them into the public decision-making and management process, can not only enhance their enthusiasm, but also achieve overall upgrade of public services quality and efficiency.

\section{Innovate public administrative system}

The actual effect of government public administration is directly related to the construction of national civil servants. To this end, it is an important task of administrative reform to learn from the experience of private operation in market economy countries in the critical period of social transformation and to comprehensively build national civil servant team. In terms of selection of relevant policies, we should actively learn from the flexible western government model, and on the basis of organs reform, effectively simplify the permanently established institutions. Combined with the actual needs, create temporary institutions, to break the restraint of life-long employee system and achieve the purpose of downsizing. Based on this, we shall attach great importance to the role of human resources, and implement electronization of public human resources management, so that the work of knowledge workers can be fully promoted. For this purpose, it is necessary to build a national civil servant team compatible with management requirements of the socialist market economy and the new era.

\section{Actively breed social intermediary organization}

The development of the market economy clearly indicates the interactive relation of government and society does not mean that the society excludes the government, or the government organizes the society. In the course of the development of Chinese history, the traditional concept of "strong government and weak society” is deeply rooted. In order to actively change this situation, promote 
marketization of the planned economy, and effectively change the government function, it is required to breed and develop social intermediary organizations, and fully improve self-government organizational structure. Through the overall training on social autonomy and self-discipline ability, the interactive, cooperative and mutually dependent relationship of government and society is expected to be formed. At the same time, give full play to in the role of the third sector in social management as the production and interaction of the third sector have obvious nature of commonweal, which is, the so-called public interest services, so that a solid foundation can be laid for the implementation of good governance.

\section{Conclusions}

In conclusion, in the new period, the country is in the key stage of reform in terms of economy, policy, culture and science, however, the market economy development is still immature, and the rule of law is also imperfect. In this case, it is a must to continue to improve the efficiency of government, and actively introduce new public management concept of western countries, based on the development, rationally learn from and absorb this concept, and then comprehensively promote the overall level of government management.

\section{References}

[1] Lou Chengwu, Dong Peng. New Public Management from Multi-dimensional Perspectives, China Administration, 2016 (7): 77-82.

[2] Leng Xianghui. Concept Change and Orientation Selection of Public Security Reform from New Public Management Perspective, Intelligence, 2015 (20): 362-362.

[3] Li Li. On "Five in One” Government Concept Construction of New Public Management , Theory, 2014 (25): 75-77.

[4] Niu Ling. On Public Sector Human Resource Management from New Public Management Perspective, Human Resource Management, 2016 (10): 15-17.

[5] Zhang Yan. State-owned Assets Management Model in Colleges from New Public Management Perspective, Nanjing University of Aeronautics and Astronautics, 2015. 